\title{
GEOGRAPHICAL PATTERNS OF ACCESS AND UTILIZATION OF BASIC HEALTH UNIT IN DISTRICT ATTOCK
}

\author{
M. Ayaz Bhatti
}

\begin{abstract}
OBJECTIVES: To measure the distance of villages from the health facility in union council Gali Jagir, District Attock and to analyze the geographical location, pattern of access and health facility utilization.

DESIGN: This was a cross sectional study.

SETTING: The study was carried out at union council Gali Jagir, Tehsil Fateh Jang, Distrct Attock from 15 November 2000 to 31 December 2000.

METHODS: Measurement of the distance from the villages to the health facility was done and the facility record was reviewed to assess the utilization pattern by the village population. Information about mode of travel, time for travel and cost of traveling was collected by the key informants.

RESULTS: Twenty-two percent of villages and $23 \%$ of population was situated within $3 \mathbf{~ k m}$ distance (by foot) from the basic health unit (BHU). Eleven percent of villages and $10 \%$ of population was situated within 3-5 km distance (by foot) from the BHU. Majority (67\%) of villages and $70 \%$ of population was situated more than $5 \mathrm{~km}$ (by foot) from the BHU. The overall health facility utilization of BHU Gali Jagir was $8.34 \%$. It was found that a distance of $3 \mathrm{~km}$ was accessible distance and the health facility utilization decreased as the distance increased. There were also other causes (financial, cultural and functional) of inaccessibility.

CONCLUSION: This study has identified the gaps in the geographical access patterns that an accessible distance is $3 \mathrm{~km}$ instead of $5 \mathrm{~km}$ (as accepted by World Health Organization). Distance of $3 \mathrm{~km}$ is accessible for seeking care from a public health care facility and overall health facility utilization was $8.32 \%$, which is alarmingly low.
\end{abstract}

KEY WORDS: Health System. Health Facility. Utilization. Access. Geography. Pakistan.

\section{INTRODUCTION}

One of the five most important principles of Primary Health Care $(\mathrm{PHC})$ is the universal coverage of the population or people's access for the health services. Accessibility implies "the continuing and organized supply of care that is geographically, financially, culturally and functionally within easy reach of the community". The geographical accessibility means "the distance, travel time and means of transportation are acceptable to the community". Vital disparities persist in the capability of the world's nations to provide a basic level of needed services to enhance the life chances of those who are the most vulnerable; the poor, the sick and the disadvantaged. The reality of these deep human scars is immense. In the context of these wide spread disparities within and among nations, the percentage of the population that does not receive health services on a permanent and continuous basis is on the increase and their problems are becoming more serious. Therefore, it is compellingly urgent to develop strategies that strengthen the access to health. The National Health
Service in United Kingdom (UK) has actively persuaded policies to reduce geographical inequalities for the last 50 years. These might include more effective transport arrangements for the people. In the UK, $97 \%$ of the population is registered with a general practitioner while in Portugal, $80 \%$ of the population is registered with general practitioners at local health centers. In Chile, health centers attend up to $97.8 \%$ of all births and $97 \%$ of all outpatient consultations. Access and utilization is a problem of the under developed countries where the health resources are limited and the health needs unlimited. In different countries like Egypt, Cameroon, South Sudan, Uganda, Tanzania, Mali, Yemen, and Malawi from 1978-1992 with the exception of Egypt, where 95 percent of the population live within reach of a health care facility, none of the others reached beyond a potential coverage of 35 percent. Distance is clearly an important factor in utilization of health services. In Uganda, the average number of outpatient visits declines by $60 \%$ for every two miles ${ }^{7}$. Health is a basic human need and therefore alters the process of development. Almost, all nations of the 
world need to develop their health systems to meet their health needs. This is particularly true of the developing countries like Pakistan where need for change is acute because of facing more problems as compared to the developed world. Developing countries like Pakistan are facing the problems of lack of resources along with their inefficient use and on the other hand under- utilization of health services. More than 5200 Basic Health Units (BHUs) and 550 Rural Health Centres (RHCs) have been established all over the Pakistan for provision of PHC to the people. But, the problem of universal coverage and accessibility is still a dream. With huge expenditures and passage of twenty-two years only $33 \%$ of the rural population is in access of $5 \mathrm{~km}$. There are also significant provincial differences with access, being best in Punjab and worst in Sindh. The use of government health care services in Pakistan is low and does not look to have improved with social action program. According to Pakistan integrated household survey (PIHS), a government health practitioner is consulted in $20 \%$ of cases.

The under-utilization of BHUs and RHCs is usually due to inaccessibility, and within the inaccessibility the geographical patterns of access are of particular importance. Perhaps, the time has come to review alternate options for delivery of publicly financed basic health care in Pakistan. The problem of geographical inaccessibility of the health facilities for the population is due to the long distance to the health facility, lack of roads and transport facilities. Other contributing factors are social and financial inaccessibility further potentiated by poor quality of care. All these factors aggregate and lead to underutilization. In many cases distance is measured in a linear way without analyzing the other contextual factors such as road quality, mode of transport, availability of transport, frequency of transport availability, time for traveling and cost of traveling. In this study, the geographical patterns of access and health facility usage in a union council of District are looked at by viewing the above-mentioned factors.

\section{MATERIAL AND METHODS}

This was a cross sectional survey for measurement of distance of villages and populations from the $\mathrm{BHU}$ Gali Jagir, District Attock. This study was carried out from 15 November 2000 to 31 December 2000. Review of facility record was done to assess the utilization pattern by the village population. Information from key informants was obtained about mode of travel, time for travel and cost of traveling. The final data was then analyzed through the SPSS 10.0 software program. Objectives of the study were to measure the distance of villages (Distance by dirt path and distance by public transport) from the facility (BHU) in union council Gali Jagir and to analyze the geographical location, pattern of access and health facility utilization.

The study was comprised of following steps:

I. Distance measurement: Measurement of distance from the village (all villages) to the health facility. This included measurement of distance by dirt path and public transport through odometer from the village to the health facility. The distance was measured from the main gate of $\mathrm{BHU}$ to the mosque of the village.

II. Mode of travel: Information regarding health facility usage, mode of travel, availability of transport, frequency of transport availability, time for travel and cost of travel was collected from the key informants of every village, which was collected through structured questionnaire.

III. Geographical location, patterns of access and health facility utilization: Facility-based review of services for availability of staff, drugs and health facility utilization (from updated community chart, outpatient department record, attendance record and stock register medicine for the year 1999-2000). Health facility utilization was analyzed in relation to distance, patterns of access and modes of travel.

\section{RESULTS}

Distance of Villages: Two of the villages were situated at by foot distance of $1 \mathrm{~km}$ and $3 \mathrm{~km}$ from the $\mathrm{BHU}$. Three villages were situated within $5 \mathrm{~km}$ and six villages were situated at by foot distance of more than $5 \mathrm{~km}$ (Range 6-14km) from the BHU. The mean by foot distance from the villages to $\mathrm{BHU}$ was $7 \mathrm{~km}$. (Table I and II). Two of the villages had no public transport for the BHU, so there was no public transport distance for these two villages. Seven villages had public transport to the BHU. The public transport distance from the village to $\mathrm{BHU}$ ranged from $8.9 \mathrm{~km}$ to $22 \mathrm{~km}$. The mean public transport distance from the villages to BHU was $10.9 \mathrm{~km}$.

Mode of travel: The two villages which were situated at by foot distance of 1 and $3 \mathrm{~km}$ from $\mathrm{BHU}$ were devoid of public transport. Among the rest of seven villages having public transport, only one of them was utilizing the $\mathrm{BHU}$ and the rest were using higher-level facility at Fateh Jang. Mean cost of travel by public transport to $\mathrm{BHU}$ was 5.6 rupees and mean cost of travel to Fateh Jang was 6.1 rupees. Mean cost of travel by public transport to Fateh Jang was $8 \%$ more than the cost of travel to BHU. Mean time for travel to $\mathrm{BHU}$ by public transport was 32 minutes and for Fateh Jang 40 minutes. Mean time for travel by public transport to Fateh Jang was 33\% more than BHU. 
Public transport distances for higher-level facility (Fateh Jang) were longer, more costly and time consuming as compared to BHU. The public transport was available for the Fateh Jang every hour and for the BHU, it was available at an interval of three hours.

Geographical location, pattern of access and health facility utilization: The village situated at by foot distance of one $\mathrm{km}$ had utilization rate of 1.2 visits per person per year. Meanwhile, the second village situated at a distance of $3 \mathrm{~km}$ had utilization rate of 0.25 visits per person per year (Scatter Plot). The patients of these two villages had no public transport. The villages which were situated at distance of more than $3 \mathrm{~km}$, BHU utilization by them was quite low ranging from 0.01 to 0.04 visits per person per year (the required is 3 visits per person per year) even though public transport was available to them. The utilization fell rapidly as the distance increased from $1 \mathrm{~km}$ to $3 \mathrm{~km}$ and at a distance of $5 \mathrm{~km}$, utilization rate was negligible. It reflects that by foot pattern of access was the best access for villages and populations living within $3 \mathrm{~km}$. Maximum utilization was at a distance of $1 \mathrm{~km}$ (though less than required) and when the distance increased just more than $3 \mathrm{~km}$ the utilization reached to zero.

In union council Gali Jagir, 22\% of villages and 23\% of populations were situated at by foot distance of $3 \mathrm{~km}$ from the $\mathrm{BHU}, 33 \%$ of villages and $30 \%$ of population were living within $5 \mathrm{~km}$. Sixty-seven percent $(67 \%)$ of villages and $70 \%$ of population were situated at by foot distance of more than $5 \mathrm{~km}$ from BHU. Twenty-two percent of the villages did not have public transport and $78 \%$ of the villages had public transport for both BHU and Fateh Jang. Health facility utilization was $38 \%$ if the by foot distance was less than $1 \mathrm{~km}, 29.6 \%$ if the distance was less than $3 \mathrm{~km}$ and $22.4 \%$ if the distance was less than $5 \mathrm{~km}$. The overall health facility utilization of BHU Gali Jagir was $8.34 \%$ during the year 1999-2000. BHU was supposed to provide coverage to $33 \%$ of villages and $30 \%$ of population as they were situated at a distance of $5 \mathrm{~km}$ (one hour walking distance). But, the BHU was covering up to a distance of $3 \mathrm{~km}$ that is $22 \%$ of villages and $23 \%$ of population.

Health facility usage by gender and age: All the patients who attended the BHU during the year 19992000 (3785 patients) were analyzed for age, sex, disease and village from which they came. Maximum health facility utilization was by the age group 15-44 years; $47 \%$ of total facility utilization was by this age group. Utilization by this group may be due to better accessibility by this age group, because this group is in better position to go by foot. Among the age group 15-44 the greater utilization was by females possibly because women in this age group are in reproductive age and they suffer more frequently by the health problems than males. Utilization was also more by females in the age group 1-4 and 5-14 years. Health facility was utilized more by males than females at two extremes of life that is $<1$ year and $>45$ years of age (Table III). Majority of villages and population were at a distance from where they were not in access with the BHU. Only 33\% of villages and $30 \%$ population was at a distance of $<5 \mathrm{~km}$. The $\mathrm{BHU}$ was accessed and utilized by villages and population situated at a distance of $<3 \mathrm{~km}$. Villages and population who were totally out of access with BHU were un-served. Therefore, the villages and population in the union council Gali Jagir were either under served or un-served.

TABLE I:

DISTANCE (IN KM) FROM VILLAGES TO BHU

\begin{tabular}{|l|c|c|c|}
\hline Name of Village & $\begin{array}{c}\text { By } \\
\text { foot }\end{array}$ & $\begin{array}{c}\text { Public } \\
\text { Transport }\end{array}$ & $\begin{array}{c}\text { Public } \\
\text { Transport } \\
\text { Fateh Jang }\end{array}$ \\
\hline Gali Jagir & 1.0 & NA* $^{*}$ & 16.0 \\
\hline Nakodar & 3.0 & NA $^{*}$ & 15.0 \\
\hline Pind Fateh & 5.0 & 12.2 & 15.0 \\
\hline Aroria & 6.0 & 11.2 & 20.0 \\
\hline Sharai Bahadar & 6.0 & 8.9 & 15.0 \\
\hline Lani wala & 7.0 & 10.0 & 16.0 \\
\hline Ismail & 9.0 & 16.5 & 21.5 \\
\hline Pagh & 12.0 & 17.3 & 22.4 \\
\hline Dewal & 14.0 & 22.0 & 27.0 \\
\hline
\end{tabular}

AND HIGHER-LEVEL HEALTH FACILITY

*NA Public transport not available

TABLE II:

DISTANCE, COVERAGE, UTILIZATION RATE AND HEALTH FACILITY UTILIZATION

\begin{tabular}{|c|c|c|c|c|}
\hline $\begin{array}{c}\text { Distance } \\
\text { by foot } \\
\text { in KM }\end{array}$ & Population & $\begin{array}{c}\text { Patients } \\
\text { in one } \\
\text { year }\end{array}$ & $\begin{array}{c}\text { Utilization } \\
\text { rate / per- } \\
\text { son/ year }\end{array}$ & $\begin{array}{c}\text { Health } \\
\text { facility utili- } \\
\text { zation \% }\end{array}$ \\
\hline$<1$ & 2401 & 2780 & 1.16 & 38.6 \\
\hline$<3$ & 3444 & 3015 & 0.88 & 29.2 \\
\hline$<5$ & 4526 & 3038 & 0.67 & 22.4 \\
\hline$<7$ & 7782 & 3124 & 0.40 & 13.4 \\
\hline$<14$ & 15124 & 3785 & 0.25 & 8.34 \\
\hline
\end{tabular}


TABLE III:

HEALTH FACILITY USAGE BY GENDER AND AGE

\begin{tabular}{|c|c|c|c|c|c|c|}
\hline Age Group & Population & Population \% & Patients & Utilization \% & $\begin{array}{c}\text { Utilization \% } \\
\text { by Females }\end{array}$ & $\begin{array}{c}\text { Utilization \% } \\
\text { by Males }\end{array}$ \\
\hline$<1$ & 334 & 2.20 & 123 & 3.2 & 1.4 & 1.8 \\
\hline $1-4$ & 1523 & 9.80 & 432 & 11.4 & 5.9 & 5.5 \\
\hline $5-14$ & 3879 & 26 & 757 & 20 & 12.6 & 7.4 \\
\hline $15-44$ & 6477 & 43 & 1803 & 47.4 & 25.2 & 22.2 \\
\hline $45+$ & 2911 & 19 & 668 & 18 & 6.2 & 11.8 \\
\hline Total & 15124 & 100 & 3785 & 100 & 51.3 & 48.7 \\
\hline
\end{tabular}

SCATTER PLOT SHOWING DISTANCE AND HEALTH FACILITY UTILIZATION

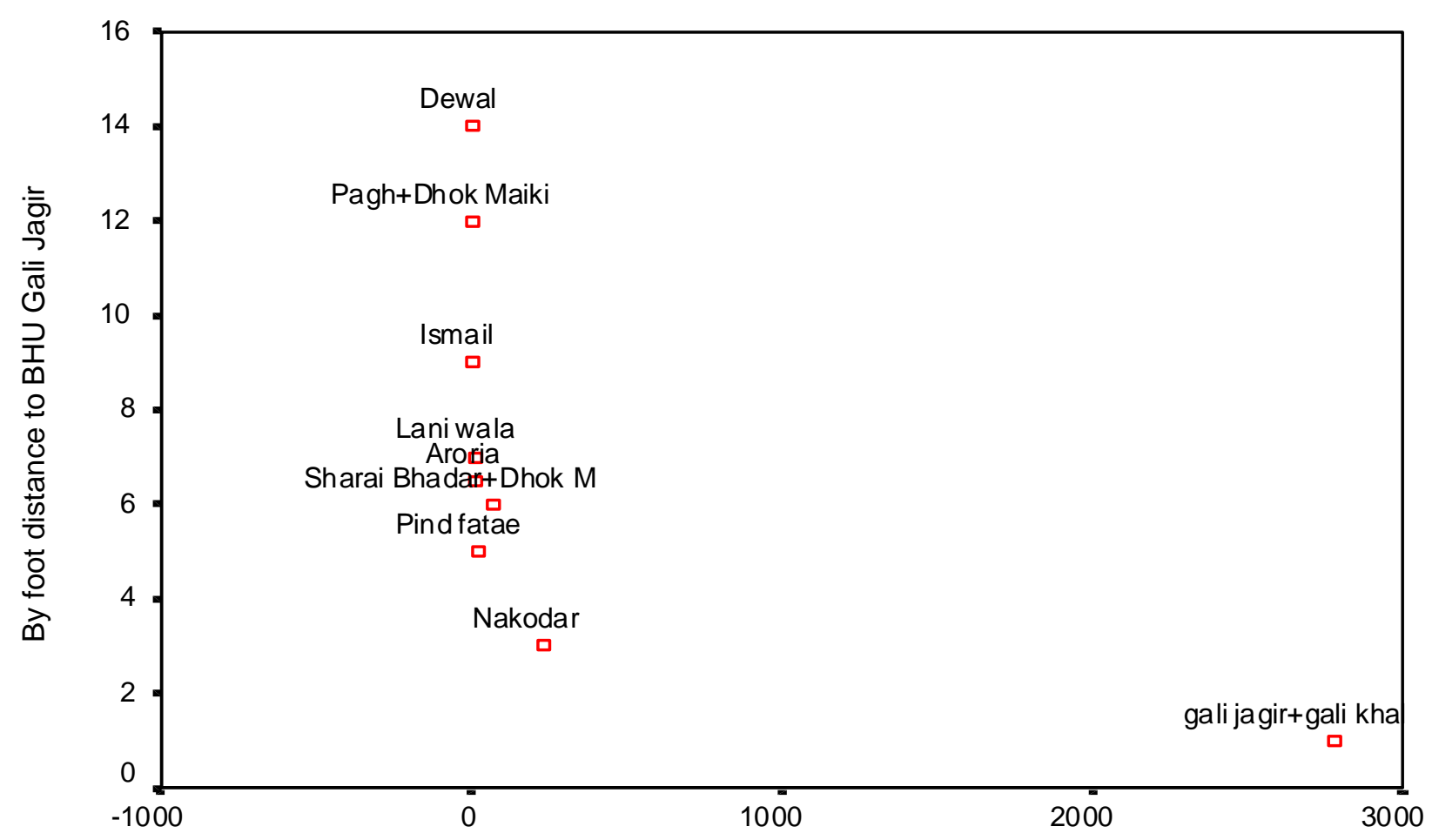

Patients per village in one year

\section{DISCUSSION}

In this study, it was observed that $67 \%$ of villages and $70 \%$ of population were situated at by foot distance of more than $5 \mathrm{~km}$, which is quite far as the universal coverage and accessibility is concerned. Population at by foot distance of $3 \mathrm{~km}$ had utilized the health facility and population at distance of more than $3 \mathrm{~km}$ had not utilized the facility. The health facility utilization decreased as the distance increased which is according to the previous studies already conducted and mentioned in the literature, but geographical accessibility up to a distance of $3 \mathrm{~km}$ is a new finding. The villages and population with available public transport were not utilizing the $\mathrm{BHU}$ but they were going to higher-level facility, even though the distance, cost and time for travel were more. Possible reason may be the distance more than $3 \mathrm{~km}$ (by foot distance) of villages, availability of public transport at larger intervals, non-availability of public transport in the odd hours, limited service 
availability at $\mathrm{BHU}$ and inconvenience in case of referral. The important point explored during the study was that only availability of public transport is not sufficient but how frequently the public transport was available is more important. This study also explores that by foot pattern of access to $\mathrm{BHU}$ is adopted by the villages and population living with in a distance of $3 \mathrm{~km}$. By foot pattern of access was the best access up to a distance of $3 \mathrm{~km}$ because the health facility utilization was maximum when by foot distance was less than $3 \mathrm{~km}$. When the distance was more than $3 \mathrm{~km}$ and the people have to go on public transport, they prefer to go to a higher-level facility. The study provides evidence that when the health facility is in access of by foot distance of $<3 \mathrm{~km}$, the other factors of under use or non-use can be improved but when all the services are available and they are not in access of population all goes in vain. Construction of one BHU in every union council without assessing the geographical patterns of access, coverage, modes of transport, frequency of availability of public transport will not solve the problem of universal access and coverage, and ultimately the goal of Health For All. In country like Pakistan, it is not possible to provide public transport to every village or to construct a $\mathrm{BHU}$ at a distance of every $3 \mathrm{~km}$. The study raises the question that at what level basic health services be strengthened and how the access and coverage can be improved. The possible ways and their pros and cons are still to be discovered.

\section{CONCLUSION}

This study has identified the gaps in the geographical access patterns that a distance of $5 \mathrm{~km}$ was not accessible to the rural populations, but a distance of $3 \mathrm{~km}$ was accessible for seeking care from a public health care facility. By foot pattern of access was the best up to a distance of $3 \mathrm{~km}$. Twenty-three percent of population had access to the health facility and within this population health facility utilization was $29.2 \%$. Thirty percent of population was under served and $70 \%$ of population was un-served even if the accessible distance of $5 \mathrm{~km}$ was taken into account.
The overall health facility utilization was $8.32 \%$, which is alarmingly low. Transport availability is important but how frequently that transport is available for a health facility is more important. Diseases like acute respiratory infection, diarrhea and malaria are still the common problems of rural area. The males and females equally utilize the health facility and there was more utilization by females in the age group 1544 years and by males in the age group $<1$ and $>45$ years. The study does not represent the entire District, Province or Country. However, this can serve as baseline for further studies on this topic.

\section{RECOMMENDATIONS}

\section{(A) For construction of new health facilities:}

- For construction of a health facility, a field and spatial survey should be conducted to see the geographical accessibility of the population for the facility.

- A health facility in the rural area should be established in an area where it could provide maximum coverage and accessibility.

- Pattern of access should be determined and availability and frequency of availability of transport should also be considered.

\section{(B) For existing health facilities:}

The emphasis should be on improving the use of existing heath facilities because large network of health facilities has already been established which is underutilized. For the improvement;

- Survey on national basis for coverage and accessibility of PHC should be conducted to determine the uncovered areas and populations. These uncovered areas should be defined for future coverage through public or private sector.

- Private practice should be licensed and license should be issued for those areas, which are uncovered and inaccessible to routine PHC.

- Provision of transport facility to the populations living away from health facility through community participation and inter-sectoral co-ordination.

- Preventive health services at village level should be strengthened through Prime Minister's Program. 
- Services and supplies be ensured at the BHU level and then strict referral system should be made functional from the village to $\mathrm{BHU}$ through Lady Health Workers and then from BHU to RHC or Taluka Head Quarter where the required facility is available.

\section{REFERENCES}

1. WHO, UNICEF. Joint report by Director General of WHO and Executive Director of UNICEF. International Conference on Primary Health Care, Alma-Ata USSR. 6-12, Sept. 1978: 28.

2. WHO. The Crises of Public Health. Pan American Health Organization 1992: 67.

3. Haynes R, Benthan G, Lovet A et al. Effects of distance to hospital and GP surgery on hospital inpatient episodes, controlling for needs and provision. Soc Sci Med 1999; 49(3):423.
4. Kahssay MH. Health centers:the future of health depends on them. World Health Forum 1998; 19(4): 341-65.

5. Kielmann AA, Neuvians D, Kipp W et al. Quality, quantity and utilization of basic health services. Health, Population, Nutrition Division, Deutsche Gesellschaft fur Technische Zusammenarbeit, GTZ, Gmbh 1993: 323-345.

6. WHO. Development of indicators for monitoring progress towards Health For All by the year 2000 . WHO Geneva 1981:46.

7. Ministry of Health. Government of Pakistan, Islamabad. National Health Management Information System. National Feedback Report. Sept.1999: 61.

8. Federal Bureau of Statistics. Government of Pakistan, Islamabad. Pakistan Integrated Household Survey. Access and usage of basic health care in Pakistan 1996:1.

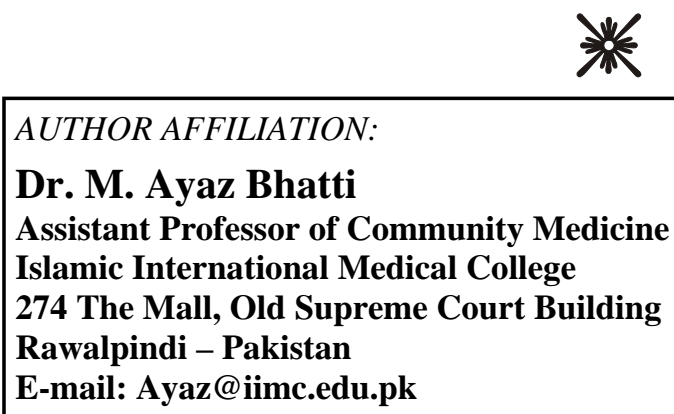

